\title{
Strategic Standardisation of Smart Systems: Roadmapping Process in Support of Innovation
}

\author{
Jae-Yun $\mathrm{Ho}^{*}$, Eoin O’Sullivan \\ Centre for Science, Technology \& Innovation Policy, Institute for Manufacturing, University of Cambridge. \\ 17 Charles Babbage Road, Cambridge, CB3 OFS, United Kingdom
}

\begin{abstract}
With increasing awareness among policymakers and other stakeholders of the importance of standards in supporting innovation, many national governments and standards organisations are taking strategic foresight approaches to standardisation. This is especially the case for ICT-based 'smart systems', where an increasing number of different technologies and systems are interconnected to each other, involving a complex variety of actors. Roadmapping is a widely used tool to support such strategic policy processes, yet there remain significant challenges in terms of structuring and managing roadmapping exercises. This paper proposes a systematic process of managing roadmapping practices to develop effective strategies for standardisation in support of innovation. Based on literature regarding public-level strategy roadmaps and reviews of existing standardisation roadmapping exercises, a more systematic process has been developed, incorporating activities and tools to address increased challenges associated with standardisation of such complex areas. Findings of the research not only provide guidance on how roadmapping processes can be structured and organised to more effectively address standardisation issues in innovation strategies for smart systems, but also highlight policy implications, including potential roles for government in supporting standardisation efforts.
\end{abstract}

Keywords. standards, standardization, strategy, foresight, roadmapping, smart systems.

\section{Introduction}

With the growing importance and pervasiveness of Information and Communications Technology (ICT), there has been increasing awareness of the importance of standards for ICT innovation since the last decades of the $20^{\text {th }}$ century. The proliferation of various technical components that need to be interconnected within larger systems presents associated standardisation challenges, requiring more anticipatory standards to achieve interoperability among networked products (Blumenthal \& Clark 1995; David \& Shurmer 1996; Jakobs et al. 2011). Many studies have been carried out, exploring important roles of standards in supporting technological innovation, including: defining and establishing common foundations upon which innovative technology may be developed; codifying and diffusing state-of-the-art technology and practices; and allowing interoperability across products and systems (Allen \& Sriram 2000; Tassey 2000; Blind \& Gauch 2009; Swann 2010; NSTC 2011). While timely and well-designed standards can support innovation, premature or inappropriate standards may have detrimental impacts on innovation, including: imposing constraints by increasing irreversibility and decreasing flexibility, locking in inferior standards or technologies (e.g. the QWERTY keyboard), and risking monopolies, especially in network industries where standards can become technological bottlenecks (David 1985; Shurmer \& Lea 1995; Hanseth et al. 1996; Swann 2000; Langlois 2001; CIE 2006).

Because of this dual nature of standards, strategic approaches for timely and appropriate standardisation are critical for innovation systems. However, this is especially challenging for complex systems integrating different technologies and subsystems, as they require not only a large infrastructure of interconnection standards, but also input from a variety of stakeholders from different organisations and disciplines (Blumenthal \& Clark 1995; NPE 2012; Tassey 2014). These systems are also continuously evolving, based on new R\&D-driven innovations of individual components and technologies. Furthermore, the pervasiveness of smart ICT-based systems in areas of critical national and societal importance - including energy (e.g. smart grids), transportation (e.g. smart mobility), and industrial productivity and competitiveness (e.g. smart manufacturing) - results in an even greater variety of stakeholder interests, regulatory issues, and policy considerations. Consequently, a more systematic

\footnotetext{
*Corresponding author: jyh25@ cam.ac.uk
} 
and anticipatory approach to strategic standardisation is called for, particularly in complex heterogeneous areas of 'smart systems'" where ICT plays a critical role.

The need for more systematic foresight approaches to standardisation has been widely recognised among policymakers and standards organisations (EXPRESS 2010; NSTC 2011; European Commission 2011). In order to address such challenges, there have been a number of future-oriented analyses for effective anticipation and management of standards. Roadmapping is one of the most widely used tools for such foresight exercises, supporting systematic planning and development of standardisation strategies. Many countries have developed standardisation roadmaps in various areas related to smart systems, as there are significant challenges and opportunities associated with standardisation in these complex areas (NIST 2010a; Hogan et al. 2011; NPE 2012; DKE 2012; TTA 2013; DKE 2014; Scapolo et al. 2014). Despite its wide adoption, there remain considerable challenges for policymakers and standards organisations in terms of how to structure and manage roadmapping for strategic foresight analyses of standardisation. Although a recent work by Featherston et al. (2015) presents a framework to support the anticipation of standards with careful characterisation of various technologies and innovation activities relevant to standardisation, more research is needed on a systematic process of organising and managing roadmapping exercises, effectively engaging and coordinating between various stakeholders and Standards Development Organisations (SDOs).

In this regard, this paper proposes a more systematic and structured process for managing roadmapping exercises to support effective standardisation in highly complex heterogeneous areas of smart systems. We begin by reviewing the existing literature on general strategic roadmapping processes. It is followed by case studies of existing standardisation roadmapping exercises, exploring the applicability of these processes and identifying key issues and challenges associated with standardisation in smart systems. This review of existing practices provides further insights into detailed activities and tools that can be adopted to address some of these issues, illustrating systematic processes of organising, managing, and governing multi-stakeholder, multidisciplinary standardisation roadmapping exercises. We conclude by discussing the implications of our findings for how roadmapping processes might be better structured and managed to effectively address standardisation issues in innovation strategies for complex areas of smart systems.

\section{Literature Review}

The most common definition of standards is provided by the International Organisation for Standardisation (ISO), which defines a standard as "... a document, established by consensus and approved by a recognised body, that provides, for common and repeated use, rules, guidelines or characteristics for activities or their results, aimed at the achievement of the optimum degree of order in a given context" (ISO/IEC 2004; cited in Andersen 2013, p.80). Standards and standardisation are explored in various domains and disciplines with different perspectives (Lyytinen et al. 2008; Narayanan \& Chen 2012). In the following sections, we give a brief overview of selected academic and practice literature, focusing on important standardisation-related factors to be accounted for strategic foresight analyses for technological innovation. In particular, we draw on this review to develop insights and an initial conceptual framework for structuring our case study analyses of standardisation roadmapping activities in smart systems.

\subsection{Roles of Standards and Standardisation}

The systematic perspective on innovation has made many scholars and policymakers aware of importance of standards as powerful institutional mechanisms that shape technological change and innovation. A variety of roles and functions of standards in innovation are thus emphasised by various innovation literature (Porter 1990; Lundvall 1992; Ehrnberg \& Jacobsson 1997; Smith 1997; Allen \& Sriram 2000; Tassey 2000; Bergek et al. 2008; Swann 2010; NSTC 2011). By providing a systematic and integrated perspective of understanding activities and key factors that influence innovation (Edquist 2001), the 'functions' of innovation systems approach appears to be particularly useful in analysing the innovation roles of standards in a structured way.

\footnotetext{
$\dagger$ Although definitions vary, the term 'smart systems' used in this paper refers to systems that, by incorporating a wide varieties of networked digital computing and communication technologies, are able to detect, analyse, and respond to the environment in performing smart actions (NIST 2010a; TTA 2013; DKE 2014).
} 
Focusing on dynamics of what is actually happening in overall innovation systems, it can also help identify potential system failures, providing rationales for policy interventions in strategic management of standardisation. By looking at how standards are accounted for in literature adopting functions of innovation systems, it is noted that standards are particularly linked to certain functions proposed by Bergek et al. (2008): legitimation, influence on the direction of search, development of positive externalities, and knowledge development and diffusion. Other literature discussing standards in the context of innovation are also reviewed, and factors corresponding to these functions are identified for coherent analyses on various roles and functions provided by standardisation in supporting innovation systems.

\subsection{1. 'Legitimation' Function of Standards}

Legitimacy is considered to be a prerequisite for new innovation systems to occur, providing the new system with appropriateness and desirability so that resources are mobilised and demand is formed (Bergek et al. 2008). Standards provide this legitimacy in two main ways. First, acting as signposts, they reduce social uncertainty and stimulate interactive learning activities by providing and communicating necessary information (Lundvall 1992; Van de Ven 1993; Edquist \& Johnson 1997). They not only reduce innovators' uncertainty about the future, encouraging them to engage in innovation, but also increase buyers' acceptance of, and confidence in, new technologies, thereby facilitating market growth and allowing subsequent innovation (Foray 1998; CIE 2006; Blind \& Gauch 2009; Swann \& Lambert 2010; European Commission 2011). Second, a consensus process of setting standards increases social acceptance, by managing and mitigating conflicts that may arise between different approaches (Carlsson \& Stankiewicz 1991).

\subsection{2. 'Influence on the Direction of Search' Function of Standards}

By helping transmit information about what routines are acceptable and providing incentives for engaging in certain innovation activities, standards have significant influence on the behaviour of actors, guiding learning activities and directions of search (Edquist \& Johnson 1997; Smith 1997). Standards also provide important technical guidance, by not only stating a target level of quality and providing some direction on how to achieve the target, but also articulating customers' demand and making them readily accessible to producers (Mansell 1995; Bergholz et al. 2006; Swann 2010; Hogan et al. 2015). Moreover, as results of converging processes towards dominant designs or specific technologies among competing possibilities, standards have significant influence on guiding the allocation of resources and other innovation efforts in certain directions, facilitating the function of 'resource mobilisation' (Porter 1990; Lundvall 1992; Van de Ven 1993).

\subsection{3. 'Development of Positive Externalities' Function of Standards}

Standards can develop positive externalities in the form of network effects - i.e. benefits to users of a system rise with increasing number of users (Smith 1997) - increasing the attractiveness for customers and leading to rapid diffusion of innovations (Ehrnberg \& Jacobsson 1997). Such externalities encourage actors to participate in other functional activities such as 'knowledge development and diffusion' and 'market formation', strengthening the overall functionality of the system (Bergek et al. 2008). For example, variety-reduction standards foster the diffusion of new products and technologies by allowing the exploitation of economies-ofscale (Blind \& Gauch 2009); measurement standards also help develop economies-of-scale by enabling advances in process control (Swann 2010). In addition, compatibility and interface standards generate positive network externalities by establishing successful linkages between various components and products, allowing more actors to join the innovation system (CIE 2006; Blind \& Gauch 2009; Swann 2010; Hogan et al. 2015).

\subsection{4. 'Knowledge Development and Diffusion' Function of Standards}

There are various ways in which standards and standardisation play significant roles in supporting the creation and transfer of new knowledge within innovation systems. As a widely-agreed and implemented baseline of accumulated technological experience, a standard provides an essential platform on which new technologies and processes can build, supporting further innovation (Hawkins 1995; Allen \& Sriram 2000; CIE 2006; Blind 2009; EXPRESS 2010). The act of standardisation itself also promotes knowledge creation, as it provides a forum of collective cognitive processes where actors with heterogeneous backgrounds discuss new ideas, enabling user-oriented, market-driven innovations (Bredillet 2003; Bergholz et al. 2006; Blind 2009; Hogan et al. 2015). In addition, standardisation is an effective channel of knowledge transfer from the R\&D 
base, where various stakeholders can share best practice and state-of-the-art research insights (OCST 1993; Tassey 2000; CIE 2006; Blind 2009). The resulting standards themselves also allow knowledge transfer and diffusion, by codifying research results and making them available to the public, thus bridging the gap between research and other stages of innovation (Blind 2002; Blind 2009; European Commission 2011).

\section{2. $\quad$ Strategic Approach to Standardisation}

Despite the important roles of standards and standardisation outlined above, strategic efforts to standardisation emerged only with the pervasiveness of ICT and associated challenges presented by it (Branscomb \& Kahin 1995). Since then, a few literature have explored strategic approaches to standardisation, even though most of these have been from a business, rather than public policy, perspective (Betancourt \& Walsh 1995; DeLacey et al. 2006). Today's technology and business environment, however, has increased policy imperatives for a strategic approach to standardisation from, in order to realise greater public benefits. Blumenthal \& Clark (1995, p.431) argue that current standardisation processes face great challenges from "the pace of technological advance, the growing number of industry sectors involved, and the lack of coherent leadership to set a long-range direction for emerging standards." As it is difficult to achieve interoperability in complex heterogeneous systems involving a variety of industry segments, a large number of standards needs to be developed in various areas and disciplines (Branscomb \& Kahin 1995). This requires not only "a combination of various standards (be they formal, de facto, or de jure), at different levels of maturity and from different SDOs (Aikin \& Cavallini 1995, p.254)," but also the coordinated engagement of these SDOs and other stakeholders.

Current challenges faced by the standards community are even more complicated with the emergence of smart systems. With more devices and applications with different technology bases interconnected to each other, as well as more data and information to be transmitted between them on a real-time basis, there is a high demand for a growing number and a variety of types of standards based on technical knowledge from various disciplines (Tassey 2014). In order to effectively meet such demands, a cross-sectoral systems thinking is required for coordination of diverse standards-related activities in different industry segments with different technology platforms (Ernst 2009; Jakobs et al. 2011; NPE 2012). As domains that have been traditionally viewed separate are now merging, resulting in new relationships among standards that did not exist before, standards need to be developed in a more systematic and integrated manner. Consequently, it would involve a variety of stakeholders with not only different backgrounds and disciplines, but also diverse interests and needs, making their coordinated engagement much more difficult. Hence, coordination-efforts at a higher system level may be needed, in order to effectively engage these stakeholders in developing standards that appropriately address their varied demands (Biddle et al. 2012). As discussed in the following section, this may require active engagement by government, which can not only provide a coherent longer-term vision of standardisation, but also "balance interests and ensure that competing perspectives are heard (Blumenthal \& Clark 1995, p.435)."

\subsection{Roles of Government in Standardisation}

Increased globalisation and economic integration has led to a growing realisation of the importance of standards as critical infrastructure for national competitiveness and economic developments, raising governmental interests in the potential of active involvements in standardisation in to support national interests (Garcia 1993; Branscomb \& Kahin 1995). This can be especially important in the context of ICT-based smart systems, as they become increasingly pervasive in infrastructure for areas of critical socio-economic importance, including energy (e.g. smart grid), transportation (e.g. smart mobility), and industrial production (e.g. smart manufacturing).

Some academic literature has suggested that there are certain areas where government interventions may actually be necessary in standardisation, with strong justifications and economic rationales for each policy activity from the system-failure perspective, including: engagement of a wider group of stakeholders, maintaining the stock of standards, collaboration between standardisation and the research community, access to standards, and coordination of different government activities (Repussard 1995; de Vries 1999; Garcia et al. 2005; Swann 2010). Based on a survey of how the federal government can effectively engage in standardisation, NIST (2010b) has also identified different modes of government engagement: 
- Convenor / coordinator: identifying needs and directions, and architectures in cross-sectoral collaborations to meet national priorities.

- Technical leader: leading SDO governance and program execution as a member of an SDO.

- Participant: members of a standards writing committee.

- Facilitator: contracting for services to enable standards writing.

- Implementer / adopter: selecting and implementing a standard, or requiring its implementation through regulation.

- Funder / enabler: funding standardisation activities of SDOs or assigning them to manage the process.

- Technical advisor: providing R\&D to support standards development or developing test methods to support a technical standard.

- Coordinator of federal agency needs: formally collaborating to address a common problem, and transferring this knowledge to an SDO.

- Interested observer: monitoring developments and assessing opportunities for engagement.

The increased interest of governments, however, presents challenges during consensus-seeking processes within international standardisation fora, where there may be national vested interests. Such challenges are further complicated by the fact that many multinational firms - which have great influence in international standards-setting given their size and global reach - may have interests which conflict with those of the nations of their origin (OTA 1992; David \& Shurmer 1996). In order to address increased challenges associated with such competing interests, various organisations at a higher policy level - e.g. quasi-government institutions or industry consortia at national / regional / international levels - may take the responsibility of coordinating a variety of stakeholders (EXPRESS 2010; European Commission 2011). However, perhaps due to the unprecedented level of complexity, current efforts for strategic approaches to standardisation in smart systems are often limited to the national level, led by national governments or government-funded standards organisations (Hogan et al. 2011; NIST 2012; NPE 2012; TTA 2013; DKE 2014).

\subsection{Roadmapping for Strategic Approach to Standardisation}

In order to address increased challenges in standardisation of smart systems, roadmapping is often used as a practical tool for effective anticipation and management of standardisation. Strategic roadmapping, with its focus on developing consensus and creating a common vision among participants, has become one of the most extensively used techniques for supporting technological innovation and management (Phaal \& Muller 2009). In particular, roadmapping frameworks are designed to support the development of coherent, holistic, and highlevel integrated view of complex systems, while displaying the interactions between various innovation activities over time (Kostoff \& Schaller 2001; Groenveld 2007; Popper 2008).

The systems-based nature of strategic roadmapping makes it useful in future-oriented analyses for standardisation (e.g. identifying standard gaps and generating plans to align necessary standardisation activities), as roadmapping can effectively identify key gaps in knowledge and their contexts (Phaal et al. 2010). In addition, it is an effective way to frame standardisation strategies within the context of broader technology strategies or existing future-oriented analyses for innovation systems, making the best use of standards and standardisation (Moreton 1999). The approach is particularly useful in areas related to smart systems, where the level of complexity requires even higher degrees of anticipatory and systematic standardisation to achieve interoperability. Consequently, a number of standardisation roadmaps have been developed for various smart system applications, including smart grid, cloud computing, electromobility, and smart manufacturing (NIST 2010a; Hogan et al. 2011; NPE 2012; DKE 2014).

These standardisation roadmaps are adopted at various levels with a variety of forms and processes, in order to suit different strategic and standardisation needs. Although careful planning and governance of the roadmapping exercise is required for effective management of roadmapping processes, there are limited studies exploring this issue, leaving significant challenges for policymakers and standards organisations in appropriately designing and organising standardisation roadmapping exercises (Miao et al. 2012; Min et al. 2012; Ho 2014). In order to fill this research gap, the current study investigates how existing standardisation roadmapping exercises have been carried out in a variety of smart system domains; it can help identify insights and potential effective practices which may offer the basis of a more systematic process of structuring and managing roadmapping for strategic foresight of standardisation in complex heterogeneous areas. 


\subsection{Roadmapping Process}

Before exploring processes of standardisation roadmapping exercises, it is appropriate to review relevant existing academic and practice literature on roadmapping processes. Although there are no hard and fast rules, the following phases have been identified as general guidelines for strategic roadmapping processes (e.g., Garcia \& Bray 1997; EIRMA 1997; Groenveld 2007; Phaal \& Muller 2009):

1) Initiation and planning: to define scope and objectives of the roadmap, and identify participants, structure, and process of developing it.

2) Input and analysis: to capture, structure, and share relevant knowledge.

3) Synthesis and output: to create the roadmap through convergence, and implement it to fulfil objectives.

4) Follow-up: to review and update the roadmap.

Detailed procedures of each phase differ depending on the purpose and type of the roadmap. Nevertheless, as the roadmapping is essentially a technique used in strategy development, they usually follow the general strategy process. Comparing published process models for business and technology strategy, Phaal et al. (2010) propose a generalised strategy process model comprising of the following steps:

1. Vision and goals: to establish a sense of direction, in terms of a future vision and goals.

2. Appraisal of current position: to collate and assess information currently available, relating to current and historical strategies, activities, and performance.

3a. Assessment of external environments: to collect and assess information relating to external factors, issues, and drivers to identify opportunities and threats.

3b. Assessment of internal environments: to collect and assess information relating to internal resources, capabilities, and constraints, to identify strengths and weaknesses.

4. Generation and assessment of strategic options: to generate strategic options, identify gaps, and assess and select the options to derive strategic plans.

5. Implementation: to put the strategic plan into action.

6. Evaluation and learning: to review outcomes and disseminate results.

Although above steps closely represent the general process of roadmapping activities to develop business strategies, further challenges exist when developing roadmaps to support innovation system-level (often public) strategy development. As such exercises often have high-level scopes, covering broader issues of collective interests with infrastructure characteristics, they not only involve a large number of stakeholders representing various perspectives, but also need to effectively draw on previous roadmapping or other similar foresight exercises. In this regard, Ho et al. (2014) have explored how roadmapping processes can be structured and managed to effectively support public strategy development, based on the case of additive manufacturing in the US. Due to a wide variety of applications and multiplicity of technological approaches, processes, and materials associated with it, a systematic approach is needed to help the community coalesce and coordinate around strategy development for supporting the industry. Examining a series of roadmapping exercises, they propose a systematic process of structuring successive roadmapping exercises that can be used to develop public-level strategies for supporting emerging technologies (see Figure 1). In particular, emphasis is put on how to gain more benefits from previous learning and analyses to enhance efficiency of the process, through various preliminary activities.

Such process may also be useful in roadmapping for strategic standardisation foresight, as they too are used to support public-level strategy developments for issues with collective interests, involving a large number of stakeholders; they include not only innovation actors with different technological knowledge and resources required for standardisation, but also those who lack such technical knowledge but are still affected by outcomes of standardisation (e.g. small companies, consumers, regulators, and governmental organisations) (Yoo et al. 2005; Swann 2010; Blind 2013). In addition, as this process is essentially based on the general roadmapping process for strategic management and technology foresight, it is readily adaptable within existing futureoriented technology analyses; hence, the process ensures that standardisation issues are addressed in a more effective and integrative way within existing foresight activities of the innovation system.

In order to further examine the applicability and usability of the process and build on it for more effective practices, the current research proposes to explore existing standardisation roadmapping exercises in smart systems. It can provide not only insights into issues and challenges associated with strategic foresight analyses 
of standardisation, but also further implications for structuring and governing roadmapping processes in such complex heterogeneous areas.

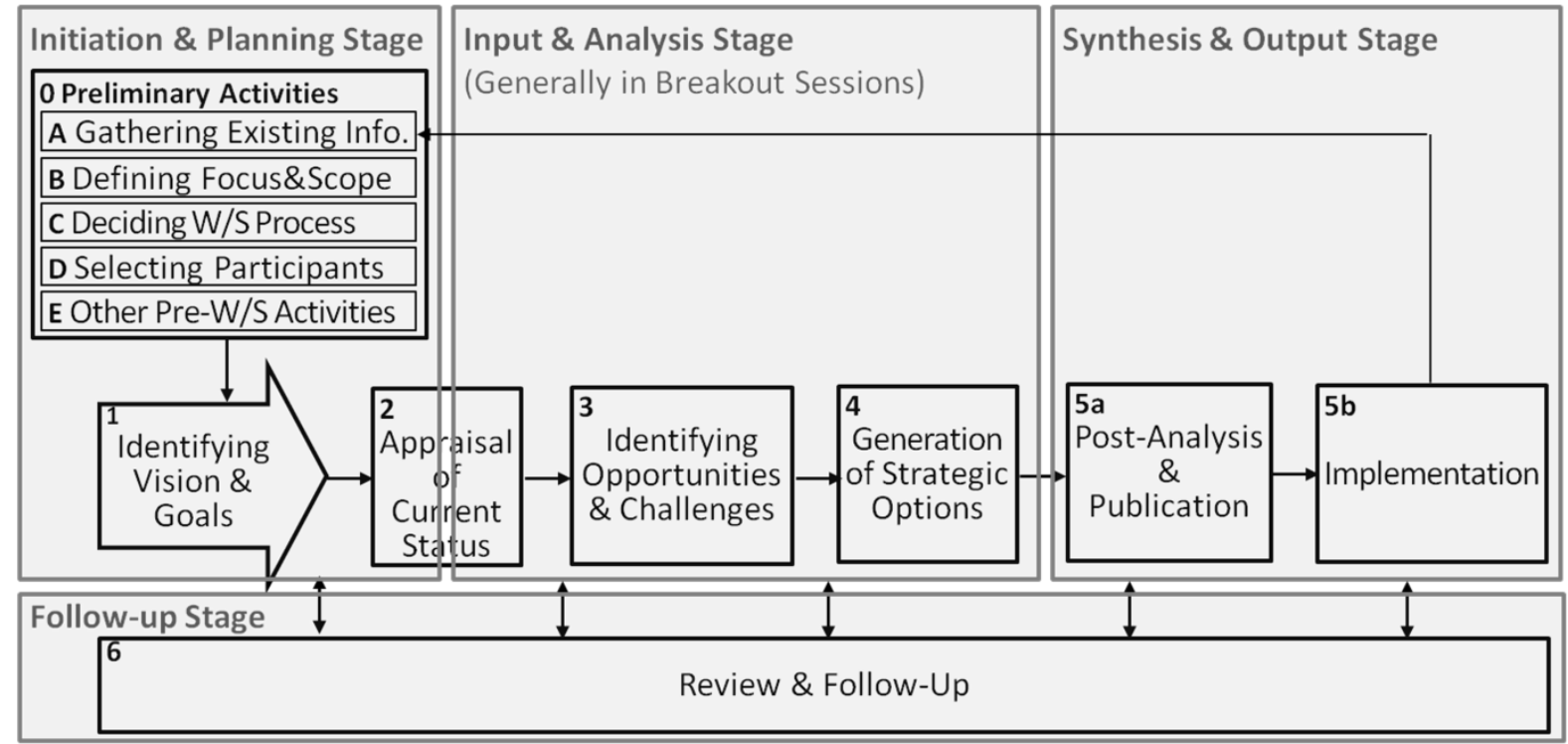

Figure 1. Process for Structuring Successive Roadmapping Exercises to Support Public-Level Strategy Developments (Ho et al. 2014)

\section{Research Methodology}

Given the complex, exploratory, and contemporary nature of the research, a case study approach has been used, allowing the researcher to develop clearer and richer explanations about a new concept based on multiple sources of data (Yin 2009). Reviewing a number of existing standardisation roadmaps in various areas of smart systems provides rich information on issues and challenges of standardisation foresight in complex areas, along with implications for more effective processes of managing roadmapping exercises. The selected roadmaps span various smart system domains, covering variations in the issues, application characteristics, and national context factors that influence standardisation:

- Case 1: National Institute of Standards and Technology (NIST) Framework and Roadmap for Smart Grid Interoperability Standards in the US

- Case 2: NIST Cloud Computing Standards Roadmap in the US

- Case 3: German Standardisation Roadmap for Electromobility

- Case 4: German Standardisation Roadmap Industrie 4.0

- Case 5: ICT Standardisation Strategy Map in Korea (for the purpose of this research, only roadmaps in focus areas related to ICT Convergence, including Smart Transport, Health ICT, Smart Home, and Green ICT, are explored)

Mostly qualitative data were collected through the desk research of archival documents, such as standardisation roadmaps and official reports, which provide reliable and detailed information on standardisation roadmapping exercises. Expert interviews with participants who have been involved in developing these roadmaps were also carried out, in order to help understand the background and details of major activities, which may be difficult to access through document sources alone; many interviews were thus conducted particularly for Case 5, complementing lack of secondary sources available. Thirty experts from various organisations participated in interviews, ensuring the representation of varied perspectives; thirteen from standards organisations, six from industry, four from research laboratories, four from government agencies, and three from academia participated. Collected information on lessons learnt from existing standardisation roadmapping practices were then analysed against the baseline model developed by Ho et al. (2014), providing implications for a systematic process of managing roadmapping exercises for strategic approaches to standardisation. 


\section{Review of Existing Standardisation Roadmapping Exercises}

\subsection{Increased Challenges in Strategic Foresight of Standardisation}

From the review of existing practices, it is shown that there exist increased challenges, thus potential areas of system failures, with strategic management and foresight analyses of standardisation in smart systems. Many of these areas have emerged from integration of various domains with different technological bases in different levels, creating a complex system of systems; this results in new points of contact and interfaces where standards are needed to allow secure interconnections and reliable communications between them. In addition, further challenges arise when existing systems need to be integrated with emerging technologies and systems, calling for more careful planning and development of standardisation strategies. Therefore, an all-encompassing, systematic approach is to be taken for comprehensive analyses of interrelationships and linkages between different technologies, allowing cross-level and cross-domain strategy developments for standardisation in such interdisciplinary areas.

The systems nature of smart systems also brings about stakeholder complexities associated with strategic approaches to standardisation; a large number of stakeholders representing various perspectives needs to be engaged, including the industry (companies, trade associations, etc.), research laboratories, academia, government, and SDOs. This leads to not only communications challenges between participants with different expertise and perspectives, but also coordination and alignment of activities performed by various innovation actors; hence, government is often actively engaged in roadmapping exercises as participants and convenors, bringing and coordinating among these actors with different interests and motivations. In addition, due to the increased complexity and systems nature, standardisation roadmaps are generally based on other supporting documents with information regarding relevant standards and standardisation activities, which need to be collated and incorporated into current roadmapping exercises. Table 1 summarises such issues and challenges with strategic management and foresight analyses of standardisation in smart systems.

Challenges and potential areas of system failures associated with standardisation of smart systems closely resemble those of public-level strategic roadmapping exercises as studied by Ho et al. (2014). There are a large number of stakeholders involved in complex systems integrating a wide variety of existing and emerging technologies; relevant information from previous studies and analyses need to be incorporated in current foresight exercises as well. Therefore, the systematic process proposed by Ho et al. (2014) can be also applicable to roadmapping exercises for strategic standardisation.

Despite the adequacy and usefulness of the proposed process, it may not be entirely sufficient to be applied for standardisation of ICT-enabled smart systems, which requires a more anticipatory and interdisciplinary approach. Hence, detailed procedures of existing roadmapping exercises are studied to explore how these challenges and potentials of system failures can be addressed more appropriately, by closely examining specific activities and practices undertaken in each practice. Although existing practices do not address all issues and challenges associated with standardisation of smart systems, lessons learnt from these exercises are expected to provide further insights and implications for how roadmapping processes can be structured, managed, and governed, in order to effectively carry out standardisation roadmapping exercises for complex heterogeneous areas from a higher level of innovation policies and strategies.

Table 1. Existing Standardisation Roadmapping Exercises in Smart Systems

\begin{tabular}{|c|c|c|c|c|}
\hline Case & $\begin{array}{l}\text { Developing } \\
\text { Organisation }\end{array}$ & $\begin{array}{l}\text { Participants } \\
\text { (order of \%) }\end{array}$ & $\begin{array}{l}\text { Role of } \\
\text { Government }\end{array}$ & $\begin{array}{l}\text { Challenges in Strategic Management and } \\
\text { Foresight Analyses of Standardisation }\end{array}$ \\
\hline $\begin{array}{l}\text { Case 1: NIST } \\
\text { Framework and } \\
\text { Roadmap for } \\
\text { Smart Grid } \\
\text { Interoperability } \\
\text { Standards } \\
\text { (NIST 2010a) }\end{array}$ & $\begin{array}{l}\text { Smart Grid and } \\
\text { Cyber-Physical } \\
\text { Systems } \\
\text { Program Office } \\
\text { of the US }\end{array}$ & $\begin{array}{l}\text { Industry, } \\
\text { Research } \\
\text { laboratories, } \\
\text { Government, } \\
\text { SDOs, } \\
\text { Academia }\end{array}$ & $\begin{array}{l}\text { Convenor / } \\
\text { coordinator, } \\
\text { Participant, } \\
\text { Funder / } \\
\text { enabler }\end{array}$ & $\begin{array}{l}\text { Due to the nature of a complex system of } \\
\text { systems: } \\
\text { - involvement of and communication } \\
\text { between a large number of stakeholders } \\
\text { with different expertise and perspectives } \\
\text { - cooperation among various SDOs } \\
\text { developing related standards } \\
\text { - integration of existing and emerging } \\
\text { systems }\end{array}$ \\
\hline
\end{tabular}




\begin{tabular}{|c|c|c|c|c|}
\hline $\begin{array}{l}\text { Case 2: NIST } \\
\text { Cloud } \\
\text { Computing } \\
\text { Standards } \\
\text { Roadmap } \\
\text { (Hogan et al. } \\
\text { 2011) }\end{array}$ & $\begin{array}{l}\text { NIST Cloud } \\
\text { Computing } \\
\text { Standards } \\
\text { Roadmap } \\
\text { Working Group }\end{array}$ & $\begin{array}{l}\text { Industry, } \\
\text { Government, } \\
\text { Research } \\
\text { laboratories, } \\
\text { Academia }\end{array}$ & $\begin{array}{l}\text { Convenor / } \\
\text { coordinator, } \\
\text { Funder / } \\
\text { enabler }\end{array}$ & $\begin{array}{l}\text { Due to the involvement of various } \\
\text { organisations with relevant standardisation } \\
\text { activities: } \\
\text { - participation and coordination of these } \\
\text { organisations } \\
\text { - collation and usage of existing supporting } \\
\text { documents }\end{array}$ \\
\hline $\begin{array}{l}\text { Case 3: The } \\
\text { German } \\
\text { Standardisation } \\
\text { Roadmap for } \\
\text { Electromobility } \\
\text { (NPE 2012) }\end{array}$ & $\begin{array}{l}\text { National } \\
\text { Platform for } \\
\text { Electromobility } \\
\text { (NPE) of } \\
\text { Germany }\end{array}$ & $\begin{array}{l}\text { Industry, } \\
\text { Government, } \\
\text { Academia, } \\
\text { Research } \\
\text { laboratories, } \\
\text { SDOs }\end{array}$ & $\begin{array}{l}\text { Convenor / } \\
\text { coordinator, } \\
\text { Tech. leader, } \\
\text { Participant, } \\
\text { Coordinator } \\
\text { of federal } \\
\text { agency needs }\end{array}$ & $\begin{array}{l}\text { Due to the integration of two separate } \\
\text { domains: } \\
\text { - coordination and integration of } \\
\text { standardisation activities required for new } \\
\text { points of contact and interfaces } \\
\text { - participation of a variety of actors from } \\
\text { different sectors }\end{array}$ \\
\hline $\begin{array}{l}\text { Case 4: The } \\
\text { German } \\
\text { Standardisation } \\
\text { Roadmap } \\
\text { Industrie 4.0 } \\
\text { (DKE 2014) }\end{array}$ & $\begin{array}{l}\text { German } \\
\text { Commission } \\
\text { for Electrical, } \\
\text { Electronics \& } \\
\text { Information } \\
\text { Technologies } \\
\text { of DIN and } \\
\text { VDE (DKE) }\end{array}$ & $\begin{array}{l}\text { Industry, } \\
\text { Academia, } \\
\text { SDOs, } \\
\text { Government }\end{array}$ & $\begin{array}{l}\text { Convenor / } \\
\text { coordinator, } \\
\text { Participant, } \\
\text { Coordinator } \\
\text { of federal } \\
\text { agency needs }\end{array}$ & $\begin{array}{l}\text { Due to the nature of a complex system of } \\
\text { systems: } \\
\text { - involvement of and communication } \\
\text { between actors from different disciplines } \\
\text { - cooperation among various SDOs } \\
\text { - integration of existing and emerging } \\
\text { systems } \\
\text { - all-encompassing approach required for } \\
\text { cross-level / cross-domain strategies }\end{array}$ \\
\hline $\begin{array}{l}\text { Case 5: ICT } \\
\text { Standardisation } \\
\text { Strategy Map } \\
\text { (particularly in } \\
\text { areas of ICT } \\
\text { Convergence) } \\
\text { (TTA 2013) }\end{array}$ & $\begin{array}{l}\text { Telecommuni- } \\
\text { cations } \\
\text { Technology } \\
\text { Association } \\
\text { (TTA) of } \\
\text { Korea }\end{array}$ & $\begin{array}{l}\text { Research } \\
\text { laboratories, } \\
\text { Industry, } \\
\text { Academia, } \\
\text { Government, } \\
\text { SDOs }\end{array}$ & $\begin{array}{l}\text { Technical } \\
\text { leader, } \\
\text { Participant, } \\
\text { Implementer } \\
\text { / adopter, } \\
\text { Funder / } \\
\text { enabler }\end{array}$ & $\begin{array}{l}\text { Due to the nature of interdisciplinary areas: } \\
\text { - all-encompassing approach required for } \\
\text { cross-level / cross-domain strategies } \\
\text { - involvement of and communication } \\
\text { between stakeholders from different } \\
\text { disciplines }\end{array}$ \\
\hline
\end{tabular}

\subsection{Illustrative Case Study of Detailed Process of Standardisation Roadmapping}

Detailed processes of the five roadmapping practices have been studied to explore how specific activities and steps they have adopted can be useful in appropriately addressing some of the organisational challenges of standardisation in smart systems. The case of NIST Framework and Roadmap for Smart Grid Interoperability Standards is shown here as an illustrative example, as it provides the richest information due to relatively long history of development and easy access to data, both from abundant archival documents and eleven expert interviews; an earlier version of this case analysis is presented by Ho (2014). It is to be noted that during the roadmapping exercise there are many iterative activities that are carried out in parallel rather than linearly as described here, as the smart grid community has been working on a variety of things at once, according to an interviewee.

\section{Step 0: Preliminary activities}

Before actual roadmapping workshops took place, existing information from previous works on smart grid were gathered, including the IntelliGrid program, the Modern Grid Initiative, and work done by the GridWise Architectural Council. Based on this information, decision was made among relevant government agencies to identify eight priority areas where there are urgent needs for smart grid-related standards; processes and participants of developing the roadmap were also decided. (NIST 2010a)

\section{Step 1: Identify vision}


Based on preliminary activities, the vision of smart grid was formulated, describing the technological and architectural destination to be described in the roadmap. The definition and characteristics of smart grid were also articulated, helping a variety of stakeholders broadly agree on what features and characteristics smart grid should have in the future. (EPRI 2009)

\section{Steps 2 \& 3: Identify existing standards and issues}

The first roadmapping workshop organised in multiple breakout sessions was held, focusing on various tasks including: defining basic system architectures, identifying current issues, and evaluating existing standards. Although it was refined and finalised in a later step, basic system architectures were first outlined, consisting of: architectural goals for smart grid; a conceptual reference model, comprised of the conceptual domain models with their actors and applications; models for smart grid information networks; a smart grid interface to the customer domain; and conceptual business services (NIST 2012). As the conceptual structure and overall organisation embodying "high-level principles and requirements that designs of smart grid applications and systems must satisfy," system architectures not only helped support communications between various stakeholders, but also identified interfaces for which interoperability standards are needed (NIST 2010a, p.19). Participants also identified current issues and key standards - either existing or available in the near future to meet smart grid needs - to be included in Catalog of Standards (CoS) (NIST 2010a).

\section{Step 4: Use case analyses to identify standard gaps, develop action plans, and refine system architectures}

The second workshop focused on identifying additional standard requirements by analysing use cases. For each use case, participants discussed how actors would interact with systems within smart grid to accomplish a specified goal (Ibrahim 2009). They then identified actors in their domains, defined information exchanges that fulfil the scenario, and finally specified relevant standard requirements that could carry these information exchanges (NIST 2010a). Requirements collected from various use cases were categorised, analysed, and compared against $\mathrm{CoS}$; the remaining requirements were assessed as known deficiencies, hence identified as standard gaps (EPRI 2009; NIST 2012). According to an interviewee, a set of priorities for addressing these standard gaps were also selected according to various factors, such as immediacy of need, relevance to highpriority smart grid functionalities, deployment state of related technologies, and estimated timeframe. Priority Action Plans (PAPs) were then generated, with a list of action items and timelines for accomplishing PAP objectives (EPRI 2009). Results of gap analyses from use cases were also used to refine system architectures, by identifying gaps in architectural principles and concepts outlined in a previous step (NIST 2010a; NIST 2012).

\section{Step 5: Publication and implementation}

An interviewee noted that a request for public comments is issued to gather additional information and resources, before publishing the final roadmap. Once published, PAPs were executed in various SDOs to accomplish the smart grid vision. (NIST 2010a)

\section{Step 6: Review and follow-up}

Throughout the first roadmapping exercise, needs for a number of modifications were recognised in terms of the governance structure of developing the roadmap, according to interviewees. First, although workshops were useful to build initial consensus and increase awareness on importance of standardisation activities, it was a laborious job to hold workshops with over 500 participants; hence, Smart Grid Interoperability Panel was established as a more structured system for an ongoing roadmapping process, providing coordination, acceleration, and harmonisation of SDOs' efforts for the timely availability of appropriate smart grid standards (NIST 2014). Second, recognising the importance of managing the overall roadmapping process, Program Management Officers were created to make sure that every process is followed smoothly, mitigating any political conflicts and modifying processes as they gain more experience throughout roadmapping exercises.

\subsection{Implications for Roadmapping Processes for Strategic Standardisation}

A close examination of five existing standardisation roadmapping practices provides insights into how some of the challenges associated with standardisation of smart systems can be addressed in actual roadmapping processes, ensuring that additional attention and organisational efforts are paid to issues related to the 
governance and organisation of roadmapping exercises. Table 2 summarises key activities and practices adopted in each case, providing implications for a more systematic process of organising and managing standardisation roadmapping exercises. Preliminary activities of gathering existing information from previous works to effectively design roadmapping workshops is a particularly important step in facilitating 'knowledge development and diffusion' function of innovation systems; it not only supports the coordinated engagement of various stakeholders, but also provides syntheses of up-to-date information and state-of-the-art research. It also helps establish common definitions of key terminologies and fundamental concepts in the beginning of roadmapping practices, which is critical for efficient communications among participants with different backgrounds and expertise. Similarly, developing system architectures at an early stage - even though they are often revised throughout the roadmapping practice - helps facilitate discussions and collaborations, by allowing participants have common understandings on the complex and interdisciplinary structure of smart systems. Providing a high-level visual conceptualisation of the overall system, it can be also used in identifying standard gaps through use case analyses, in order to achieve interoperability between different domains and systems composed of different technology bases. As a structured way of anticipating future standards needs for highly complex systems, the use case method is an important tool adopted in many standardisation roadmapping exercises, enhancing 'legitimation' function of standards in innovation systems by reducing uncertainties.

Table 2. Implications from Case Studies for Detailed Activities of Standardisation Roadmapping Exercises

\begin{tabular}{|c|c|c|c|}
\hline $\begin{array}{l}\text { Phases of } \\
\text { Road- } \\
\text { mapping } \\
\text { Process }\end{array}$ & $\begin{array}{l}\text { Steps of Public- } \\
\text { Level Strategic } \\
\text { Roadmapping } \\
\text { (Ho et al. 2014) }\end{array}$ & $\begin{array}{l}\text { Activities and Practices Used in Existing } \\
\text { Standardisation Roadmapping Exercises } \\
\text { (with Cases Illustrating Particular } \\
\text { Activities) }\end{array}$ & $\begin{array}{l}\text { Proposed Activities for } \\
\text { Managing Standardisation } \\
\text { Roadmapping Exercises }\end{array}$ \\
\hline \multirow{9}{*}{$\begin{array}{l}\text { Initiation } \\
\& \\
\text { Planning }\end{array}$} & 0. Preliminary & - Gather existing information $(1,3,5)$ & - Gather existing information \\
\hline & \multirow[t]{2}{*}{ Activities } & - Identify focus areas $(1,5)$ & - Identify scope \\
\hline & & - Decide processes \& participants $(1,3,5)$ & - Decide processes \& participants \\
\hline & \multirow[t]{6}{*}{ 1. Vision \& Goals } & - Identify vision $(1,2,3,5)$ & - Identify vision, goals \& \\
\hline & & - Identify objectives (4) & objectives \\
\hline & & - Define major elements $(1,2,3,4,5)$ & - Define fundamental concepts \\
\hline & & - Scenario planning $(2,5)$ & (by scenario planning, developing \\
\hline & & - Conceptual model $(1,2,3,5)$ & conceptual models, or defining \\
\hline & & - Define essential characteristics $(1,2)$ & essential characteristics) \\
\hline \multirow{9}{*}{$\begin{array}{l}\text { Input \& } \\
\text { Analysis }\end{array}$} & \multirow{3}{*}{$\begin{array}{l}\text { 2. Appraisal of } \\
\text { Current Status }\end{array}$} & - Identify current activities $(3,4,5)$ & - Identify current standards \& \\
\hline & & - Identify existing standards $(1,2,3,4)$ & standardisation activities \\
\hline & & - Design basic system architectures $(1,2)$ & - Design basic system architectures \\
\hline & 3. Identifying & - Identify current technical / non-technical & - Analysis of national / \\
\hline & Opportunities \& & issues $(1,3,4,5)$ & international environments: \\
\hline & Challenges & - SWOT analysis $(3,5)$ & $\begin{array}{l}\text { technical / non-technical issues } \\
\text { (e.g. SWOT analysis) }\end{array}$ \\
\hline & \multirow{6}{*}{$\begin{array}{l}\text { 4. Generation of } \\
\text { Strategic Options }\end{array}$} & - Identify gaps $(1,2,5)$ & - Gap analysis (by developing use \\
\hline & & - Develop use cases $(1,2,3)$ & cases) \\
\hline & & - Refine system architectures (1) & - Refine system architectures \\
\hline \multirow{6}{*}{$\begin{array}{l}\text { Synthesis } \\
\& \text { Output }\end{array}$} & & - Establish strategic priorities $(3,5)$ & - Establish priorities based on \\
\hline & & - Develop action plans $(1,3,4,5)$ & strategic importance \\
\hline & & - Cross-review of action plans $(1,5)$ & - Develop action plans \\
\hline & 5. Publication \& & - Wider public review process $(1,4)$ & - Review process \\
\hline & Implementation & - Execute action plans $(1,2,3)$ & - Execute action plans \\
\hline & & - Provide guidelines for strategies $(2,3,4,5)$ & - Guidelines for strategic decisions \\
\hline \multirow[t]{2}{*}{ Follow-up } & 6. Review \& & - Feedback from participants (5) & - Obtain feedback for evaluation \\
\hline & Follow-up & - Modify structure / process (1) & - Modify process if necessary \\
\hline
\end{tabular}




\subsection{Other Policy Implications for Standardisation Roadmapping}

\subsubsection{Participation of a Variety of Innovation System Stakeholders}

Most interviewees highlighted the importance of participants in standardisation roadmapping, as the roadmap heavily relies on the knowledge and insights they bring into the process. In addition, stakeholders from different types of organisations have different perspectives, thus different contributions. According to multiple interviewees, participants from the industry - including manufacturers, service providers, and utilities - provide substantial knowledge and resources on what customers really want and how systems actually work, as they are at the cutting edge of the industry with a better understanding of current market trends. On the other hand, participants from research organisations provide more state-of-the-art knowledge of technologies still at research stages, whereas participants from academia tend to offer longer-term views that increase overall values in the industry and society, but other participants may not yet be aware of.

Hence, selecting an appropriate mix of participants from various stakeholder organisations is considered critically important to ensure a balance of contributions and perspectives. Interviewees from Korea expressed their concerns that roadmaps mainly developed by researchers with purely technical perspectives may potentially overly generate research-oriented standard gaps which do not address real needs of the industry. On the other hand, interviewees from the US pointed out that dominant participation from the industry may possibly result in focusing on short-term benefits only, as their main objective is to create economic values through business models. Such imbalance of important perspectives of the overall system may lead to standardisation activities that guide innovation systems in an inappropriate direction. Therefore, a well-balanced participation of stakeholders representing various perspectives - including those of researchers, private companies, economists, market analysts, and regulators - is often essential, so that standards can effectively support the efficient development and timely diffusion of new innovation.

\subsubsection{Potential Roles of Government}

The participation of various stakeholders with different perspectives calls for an active engagement of government or other public organisations as convenor or coordinator in standardisation roadmapping. Many interviewees noted that government can facilitate collaboration of a variety of innovation actors by helping them coordinate and align their activities in a more systematic way, supporting the effectiveness and efficiency of the overall innovation system. The mediating role of government may also include helping resolve conflicts between various stakeholders or innovation systems, or helping gain legitimacy and increase social acceptance, which are critical functions of standardisation in innovation systems.

According to multiple interviewees, this convening and brokering role of government in standardisation is becoming increasingly important with the growth of ICT-enabled smart systems, where their complex heterogeneous nature requires various stakeholders with different backgrounds and interests to work together, resulting in additional challenges in communication and cross-sectoral cooperation. Various SDOs with different expertise also need to work together, requiring coordination of their activities and harmonisation of standards developed by them. In addition, there are multiple federal departments and agencies involved in supporting the development of smart systems, whose standardisation efforts and interests need to be coordinated as well. Therefore, government may have a useful role in helping to convene such a wide variety of actors, and to align their standardisation efforts related to complex innovation system challenges.

Even when such convening and coordinating role can be conducted by other organisations (e.g. non-profit industry consortia as in Case 5), government may still play active roles in standardisation roadmapping, especially in areas of national economic or societal importance. ICT convergence in Korea, cloud computing in the US, and smart manufacturing in Germany are all considered to be areas of strategic importance for national economic competitiveness. Whereas smart grid and electromobility standards support important national infrastructures, and hence serve as critical public good resources - i.e. goods whose benefits are available to everyone and from which no one can be excluded (Kindleberger 1983). Since public goods are not only typically under produced, but also subject to considerable market and system failures (Tassey 2000; Garcia 2004; Garcia et al. 2005; NIST 2010b), government needs to play a more active role in supporting the 
development of relevant standards, which are critical for effective operations of such infrastructures (as shown in Case 1 and Case 3).

\section{Proposed Process of Roadmapping for Strategic Standardisation}

Based on the public-strategy roadmapping process proposed by Ho et al. (2014) as well as lessons learnt from case studies, a more systematic and structured process is developed for managing roadmapping exercises, to effectively address some challenges related to strategic foresight of standardisation for highly complex heterogeneous systems. In particular, incorporating useful steps and activities adopted in actual roadmapping practices, the proposed process helps ensure that appropriate levels of additional care, systematic attentions, and organisational efforts are paid to issues such as governance, stakeholder inputs, benchmarking, and system characterisations. This process is summarised in Figure 2. The actual process would be more complex, dynamic, and iterative in nature, but it is still helpful to begin with a structured and rational view based on systems and process thinking (Phaal et al. 2010). A step-by-step description of the process is presented, with illustrative examples from case studies.

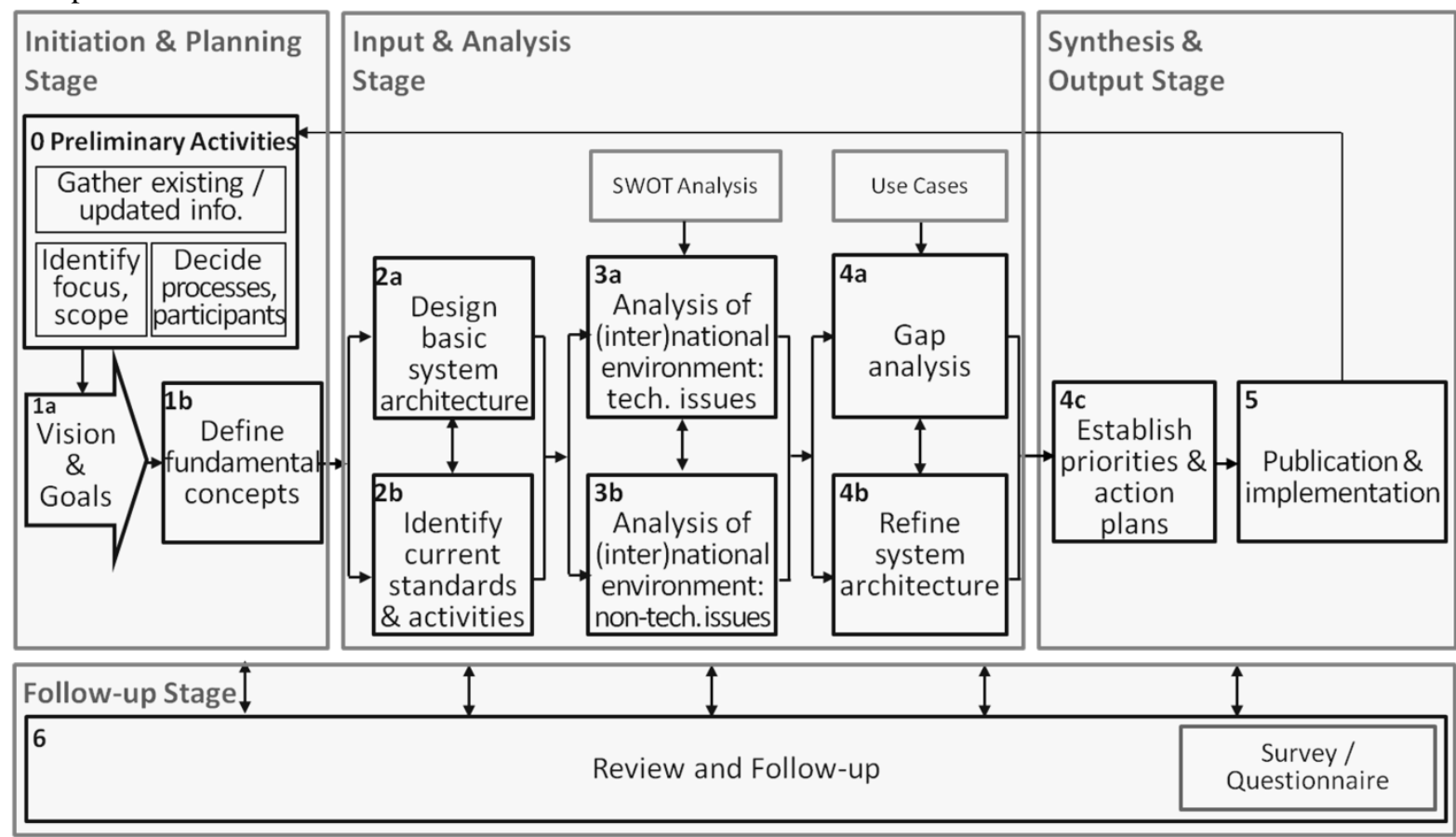

Figure 2. Proposed Process of Managing Standardisation Roadmapping Exercises for Smart Systems

\section{Step 0: Preliminary activities}

Preliminary activities during the planning and initiation phase are repeatedly highlighted in most cases, as an important first step of standardisation roadmapping exercises. Existing information is gathered from previously generated reports and foresight analyses on relevant issues, in order to access as much current knowledge and state-of-the-art understanding of the technology and its standardisation landscape as possible. Standardisation roadmaps in Case 1, Case 2, and Case 3 are actually built on previously published supporting documents (NPE 2010; NIST 2010a; Hogan et al. 2011). As they are often syntheses of collective experiences and up-to-date knowledge representing various perspectives, using this information can significantly enhance efficiency of the roadmapping process and quality of outputs.

Based on existing information gathered, the focus of the roadmap needs to be defined to help clarify scope and boundaries of the roadmap, as well as processes of how the roadmapping exercise is actually going to be run and executed. Workshops with breakout sessions can be employed to foster collaborations and interactions among various stakeholders; discussion topics in each breakout session can be designed according to the themes that appear to be important from previous analyses, as adopted in Case 1 and Case 3. Selecting roadmapping participants is another essential step, as the roadmap heavily relies on the knowledge and insights they bring into 
the process; section 4.4.1 discusses that selecting the right mix of participants from various organisations representing a variety of perspectives is critical in order to collect a balanced view of the innovation system.

\section{Step 1a: Identify visions and goals}

When the actual roadmapping workshop begins, a future vision of the field and its broad goals in terms of standardisation need to be shared and agreed among participants, in order to establish a common sense of direction which is critical for the success of strategic standardisation. Although it is difficult to achieve consensus on definite goals of standardisation in such complex systems, it is necessary to define an initial highlevel vision to develop common strategies (Emerging Industries 2001; Phaal et al. 2010). Articulating objectives and expected outcomes of roadmapping may also help guide the general direction of the roadmap.

\section{Step 1b: Define fundamental concepts}

Standardisation of smart systems involves participation of a variety of stakeholders with different backgrounds and expertise, leading to increased challenges for communication; additional confusions and ambiguities may also exist due to new terminologies and vocabularies relevant to emerging technologies. Common definitions of fundamental concepts relevant to the system under consideration thus need to be defined, in order to ensure that they speak the same language from the early stage of roadmapping exercises. It can not only facilitate communications among participants during roadmapping exercises, but also reduce uncertainties, thereby supporting 'legitimation' and 'knowledge diffusion' functions of standards in innovation systems (see sections 2.1.1 and 2.1.4). Due to the systems nature of smart systems involving a lot of information exchange, defining major elements of information systems such as main components, domains, actors, and service models can play an important role in providing better understanding of the technology (NPE 2010; NIST 2010a; Hogan et al. 2011; TTA 2013). Sometimes, tools such as scenario planning and conceptual models, as adopted in Case 2 and Case 5, may facilitate this process, by allowing a clearer overview of the system (Hogan et al. 2011; TTA 2013); however, the lack of structured methods of developing and evaluating scenarios may result in complexities due to an unhelpfully wide variety of different types in terms of form and content, as criticised by some interviewees. For domains involving integration of existing and emerging systems, it is more efficient to first define the existing system landscape coherently and completely, before defining the additional level of integration and its emergent behaviour (DKE 2014).

\section{Step 2a: Design basic system architectures}

"An architecture models the structure of a system and describes the entities and interactions within the system. (NIST 2010a, p.28)" Designing basic system architectures based on currently available information and knowledge not only allows systematic analyses of interrelationships between different technologies, but also supports communications between various stakeholders with different expertise, hence facilitating cross-domain strategic standardisation as in Case 1 and Case 2 (NIST 2010a; Hogan et al. 2011). Allowing efficient dissemination of technical information and forming a baseline from which new technologies and innovations emerge, basic system architectures can thus enhance the 'knowledge development and diffusion' function of standards in innovation systems (refer to section 2.1.4). In addition, it can be used as a tool for identifying standard requirements to ensure interoperability of the overall system. It may not be practical to develop a definite, single, and all-encompassing architecture for a complex system of systems such as smart grid and smart manufacturing; independent, yet interconnected architectures for subsystems can be developed instead, which are continuously revised as the technology evolves over time and as a higher level of consensus is reached throughout the roadmapping process (NIST 2010a).

\section{Step 2b: Identify current standards and standardisation activities}

Once basic system architectures are defined, it can be used to analyse and communicate the present standardisation landscape, as it is "a conceptual reference model for discussing the characteristics, uses, behaviour, and other elements of... (the system) and the relationships among these elements (NIST 2010a, p.28)." Current status of standards and standardisation activities relevant to complex smart systems can be discussed and organised with reference to system architectures, as adopted in most cases (NPE 2010; NIST 2010a; DKE 2014). Since most smart systems emerge from the integration of previous generation technologies with varieties of ICT, existing standards that are relevant to smart systems are originally developed in support of 
pre-exiting, analogous technologies; for example, some of the existing standards relevant to cloud computing are originally designed for web services and the Internet (Hogan et al. 2011). Hence, relevant standards and standardisation activities should be identified by examining current standardisation landscape of existing, related technologies.

\section{Step 3: Analysis of national / international environments: technical / non-technical issues}

Once current status of the standardisation landscape is identified, national and international environments need to be analysed, in order to identify opportunities and challenges in terms of standardisation; more structured tools such as SWOT analysis can be helpful, as in Case 5 (TTA 2013). This step is particularly important for standardisation roadmaps whose goal is to secure national competitiveness of the industry in international markets (NPE 2010; TTA 2013; DKE 2014). Moreover, it is critical to consider various perspectives other than just technological issues, as standards influence and are influenced by various innovation activities. Many interviewees highlighted the importance of ensuring well-balanced representations of various perspectives, including technology, market, industry, regulations (including intellectual property), and government policies.

\section{Step 4a: Gap analysis}

In order to address challenges and opportunities identified in the previous step, gap analysis is then performed, identifying key areas where standards are needed to support the innovation system. A structured method of use cases (adopted in Case 1, Case 2, and Case 3) can be a useful tool for anticipating future directions of technologies and relevant standards needs. Describing how systems would interact from a utilitycentric perspective with the aid of system architectures, use cases help determine standard requirements to achieve interoperability within various parts of the system; these requirements are then compared against the list of existing standards or current standardisation activities, in order to identify standards gaps that need to be closed in the future (NPE 2010; NIST 2010a; Hogan et al. 2011). Use case methods allow maximum innovation in emerging areas with high uncertainties, yet ensuring their ready deployment and interoperability within the system (NIST 2010a), thus reinforcing the 'knowledge development and diffusion' function of standardisation in innovation systems (refer to section 2.1.4).

\section{Step 4b: Refine system architecture}

Gap analysis from use cases may also reveal any gaps in the architectural principles and concepts that have not been aware earlier, noted an interviewee from Case 1. Hence, the basic, simpler version of system architectures designed in Step 2a can be refined, by incorporating additional requirements identified through use cases; providing a common framework of reference, refined architectures can be used to describe, discuss, and develop strategic action plans for standardisation.

\section{Step 4c: Establish priorities and action plans}

Standards gaps identified through use case analyses are then assessed in terms of various factors, e.g. strategic importance, urgency, and estimated timeframe, in order to prioritise and develop action plans to address them. Strategic options and detailed plans for each action are then generated, including whether to develop new standards or revise existing standards, identifying which SDOs should be responsible for standardisation activities, and detailed timelines for each task. Interviewees from Case 1 and Case 5 noted the importance of reviewing strategic action plans across related domains and systems, in order to ensure consistency and effectiveness of strategies developed. Due to the systematic and interdisciplinary nature of smart systems, comprehensive reviews of interrelationships and linkages between different domains and their standardisation activities are critical to support overall innovation systems more effectively. For standardisation roadmaps with objectives to secure national competitiveness of the industry, strategic positions - whether to be an active participant, co-operator, or observer - in international standardisation may be also determined, as in Case 3 and Case 5 (NPE 2010; TTA 2013).

\section{Step 5: Publication and implementation}

A draft version of the roadmap may go through a public review process, in order to engage wider stakeholders who did not have opportunities to participate in roadmapping workshops (as observed in Case 1 
and Case 4). Developed strategies may then be implemented by various organisations, influencing the selection, prioritising, and timing of standardisation activities in relevant committees. According to multiple interviewees, roadmaps can trigger various activities by both public and private decision makers in supporting smart systems industries. In addition, as syntheses of up-to-date knowledge, they may be used as critical sources of information for subsequent foresight analyses in relevant fields; for example, contents of the Cloud Computing Standards Roadmap in Case 2 are incorporated into a wider Cloud Computing Technology Roadmap (Hogan et al. 2011; Badger et al. 2011), while contents of the German Standardisation Roadmap for Electromobility in Case 3 are incorporated in a similar roadmap developed by the Transatlantic Economic Council (NPE 2012).

\section{Step 6: Review and follow-up}

As roadmapping is an ongoing learning process rather than a single, one-off activity, it is important to continuously review and revise its development process through evaluation and learning, in order to support ongoing knowledge management. Feedback from participants is critical to improve the overall roadmapping process, so surveys or questionnaires may be employed (as observed in Case 5). Based on these feedbacks as well as learning from experiences, processes and relevant governance structures of roadmapping exercises can be modified where necessary (as observed from Case 1).

\section{Concluding Remarks}

This paper presents a novel systematic process of supporting future-oriented analyses for standardisation designed, in particular, for highly complex heterogeneous smart systems, where there are increased challenges of achieving interoperability between systems with different technological bases. The proposed process is intended to better support the effective organisation, management, and governance of standardisation roadmapping exercises, ensuring that appropriate attention is given to diverse stakeholder interests, as well as complex technology and policy considerations of smart systems. Based on public-level strategic roadmapping processes presented in existing literature, the process has been developed through the study of five major standardisation roadmapping exercises in various smart system domains. The case studies provide insights into the growing challenges and potential for system failures associated with complex standardisation efforts, particularly in emerging technologies with interdisciplinary systems nature, involving various stakeholders from different organisations and disciplines. The study also provides illustrative examples of specific activities and tools that may be effective in addressing these challenges, highlighted in an in-depth case study of the NIST Framework and Roadmap for Smart Grid Interoperability Standards. Useful practices for addressing some of the organisational challenges of standardisation in smart systems include: gathering existing information for increased efficiency; establishing common definitions of fundamental concepts and developing system architectures at an early stage; and structured methods of use cases to identify standards gaps. In addition, other policy implications are drawn out, including issues of participating stakeholders and important roles of government (particularly in areas where there are issues for national competitiveness, security, and societal infrastructure) in standardisation roadmapping exercises.

Based on these findings, a more systematic and structured process of organising and managing roadmapping exercises is proposed, focused on ensuring that appropriate levels of systematic attention and organisational effort are paid to address increased standardisation challenges of smart systems. In particular, the process introduces a number of effective new steps to existing roadmapping process frameworks, incorporates other useful practices within existing steps, and refines some activities and techniques. It is important to note that the proposed process framework is designed to help address challenges associated with organisation, management, and governance of standardisation roadmapping exercises. This complements the recent study by Featherston et al. (2015) presenting a framework with careful characterisation of various technologies and innovation activities relevant to standardisation, in order to ensure that the standardisation roadmap itself is configured to address challenges due to technical complexities, multiple stakeholders involved, and interdisciplinary nature of the particular technological system under consideration.

While future research should help refine the proposed process, the framework and principles identified in this paper provide valuable insights for standards organisations and policymakers when developing roadmaps to support strategic foresight analyses for standardisation in complex heterogeneous areas of smart systems. It 
informs not only how such roadmapping exercises can be structured and managed, but also how they can be governed, identifying potentially important roles that government or other public organisations can play as coordinators. Although national governments played important roles in all cases considered in this paper, the proposed process should be also employable by other large, diverse multi-stakeholder organisations - such as public agencies or industry consortia - for strategic approaches to standardisation in areas where a systematic, integrated, and high-level perspective is needed.

\section{Acknowledgements}

The authors would like to thank Gatsby Charitable Foundation and Samsung Scholarship Foundation for their financial support, and all interviewees for sharing their knowledge and experiences, which provided invaluable insight for the research. Thanks are also due to two anonymous reviewers who provided constructive feedback and suggestions, which made the paper much stronger than before.

\section{References}

Aikin, R.J. \& Cavallini, J.S., 1995. When Are Standards Too Much of a Good Thing? Will They Provide Interoperability for the National Information Infrastructure? In B. Kahin \& J. Abbate, eds. Standards Policy for Information Infrastructure. Cambridge, Massachusetts: The MIT Press, pp. 253-275.

Allen, R.H. \& Sriram, R.D., 2000. The Role of Standards in Innovation. Technological Forecasting and Social Change, 64(2-3), pp.171-181.

Andersen, F.S.D., 2013. Standards and Innovation: A Systematic Literature Review. In Proceedings of the 17th EURAS Annual Standardisation Conference: Boosting European Competitiveness. Brussels, pp. 77-91.

Badger, L. et al., 2011. US Government Cloud Computing Technology Roadmap Volume I, Gaithersburg, MD. Available at: http://nvlpubs.nist.gov/nistpubs/SpecialPublications/NIST.SP.500-293.pdf [Accessed November 18, 2013].

Bergek, A. et al., 2008. Analyzing the functional dynamics of technological innovation systems: A scheme of analysis. Research Policy, 37(3), pp.407-429.

Bergholz, W., Weiss, B. \& Lee, C., 2006. Benefits of standardization in the microelectronics industries and their implications on nanotechnology and other innovative industries, Geneva, Switzerland. Available at: http://www.iec.ch/about/globalreach/academia/pdf/bergholz-1.pdf [Accessed May 25, 2015].

Betancourt, D. \& Walsh, R., 1995. The evolution of strategic standardization management. StandardView, 3(3), pp.117-126.

Biddle, B. et al., 2012. The Expanding Role and Importance of Standards in the Information and Communications Technology Industry. Jurimetrics, 52, pp.177-208.

Blind, K., 2002. Driving forces for standardization at standardization development organizations. Applied Economics, 34(16), pp.1985-1998.

Blind, K., 2009. Standardisation as a Catalyst for Innovation. Inaugural Address Research in Management Series. Available at: http://papers.ssrn.com/sol3/papers.cfm?abstract_id=1527333 [Accessed November 26, 2012].

Blind, K., 2013. The Impact of Standardization and Standards on Innovation, Available at: http://www.innovation-policy.org.uk/share/14_The Impact of Standardization and Standards on Innovation.pdf [Accessed May 25, 2015]. 
Blind, K. \& Gauch, S., 2009. Research and standardisation in nanotechnology: evidence from Germany. The Journal of Technology Transfer, 34(3), pp.320-342.

Blumenthal, M. \& Clark, D., 1995. Excerpts from Realizing the Information Future: The Internet and Beyond. In B. Kahin \& J. Abbate, eds. Standards Policy for Information Infrastructure. Cambridge, Massachusetts: The MIT Press, pp. 430-439.

Branscomb, L.M. \& Kahin, B., 1995. Standards Processes and Objectives for the National Information Infrastructure. In Standards Policy for Information Infrastructure. Cambridge, Massachusetts: The MIT Press, pp. 3-31.

Bredillet, C.N., 2003. Genesis and role of standards: Theoretical foundations and socio-economical model for the construction and use of standards. International Journal of Project Management, 21(6), pp.463-470.

Carlsson, B. \& Stankiewicz, R., 1991. On the nature, function and composition of technological systems. Journal of Evolutionary Economics, 1(2), pp.93-118.

CIE, 2006. Standards and the economy, Available at:

http://www.thecie.com.au/content/publications/Economic_impact_of_standards.pdf [Accessed May 23, 2013].

David, P. a \& Shurmer, M., 1996. Formal standards-setting for global telecommunications and information services. Towards an institutional regime transformation? Telecommunications Policy, 20(10), pp.789815.

David, P.A., 1985. Clio and the Economics of QWERTY. American Economic Review, 75(2), pp.332-337.

DeLacey, B.J. et al., 2006. Strategic Behavior in Standard-Setting Organizations. SSRN Electronic Journal. Available at: http://www.ssrn.com/abstract=903214 [Accessed July 12, 2015].

DKE, 2012. The German AAL Standardization Roadmap, Frankfurt. Available at: http://www.dke.de/de/std/AAL/documents/german aal standardization roadmap.pdf [Accessed November 10, 2013].

DKE, 2014. The German Standardization Roadmap Industrie 4.0, Frankfurt. Available at: https://www.dke.de/de/std/documents/rz_roadmap industrie 4-0_engl_web.pdf [Accessed May 24, 2015].

Edquist, C., 2001. The Systems of Innovation Approach and Innovation Policy: An account of the state of the art. In DRUID Conference. Aalborg, pp. 1-24. Available at: http://folk.uio.no/ivai/ESST/Outline V05/edquist02.pdf [Accessed November 5, 2012].

Edquist, C. \& Johnson, B., 1997. Institutions and Organizations in Systems of Innovation. In C. Edquist, ed. Systems of Innovation: Technologies, Institutions and Organizations. London: Pinter, pp. 41-63.

Ehrnberg, E. \& Jacobsson, S., 1997. Technological Discontinuities and Incumbents' Performance: An Analytical Framework. In C. Edquist, ed. Systems of Innovation: Technologies, Institutions and Organizations. London: Pinter, pp. 318-341.

EIRMA, 1997. Technology Roadmapping - delivering business vision, Paris.

Emerging Industries, 2001. Technology Planning for Business Competitiveness: A Guide to Developing Technology Roadmaps, Canberra, Australia.

EPRI, 2009. Report to NIST on the Smart Grid Interoperability Standards Roadmap - Post Comment Period Version, Palo Alto, CA. Available at: http://www.nist.gov/smartgrid/upload/Report_to_NIST_August10_2.pdf [Accessed March 3, 2014]. 
Ernst, D., 2009. Challenges for Standards and Innovation Policies in the Emerging Global Knowledge Economy. Available at:

https://www.google.co.uk/search?q=Challenges+for+Standards+and+Innovation+Policies+in+the+Emergi ng+Global+Knowledge+Economy\&rlz=1C1TEUA_enUS632US632\&oq=Challenges+for+Standards+and +Innovation+Policies+in+the+Emerging+Global+Knowledge+Economy\&aqs=chrome..6 [Accessed September 16, 2015].

European Commission, 2011. A strategic vision for European standards: Moving forward to enhance and accelerate the sustainable growth of the European economy by 2020, Brussels. Available at: http://eurlex.europa.eu/LexUriServ/LexUriServ.do?uri=COM:2011:0311:FIN:EN:PDF [Accessed January 23, 2013].

EXPRESS (The Expert Panel for the Review of the European Standardisation System), 2010. Standardization for a Competitive and Innovative Europe: a Vision for 2020, Available at: http://ec.europa.eu/enterprise/policies/europeanstandards/files/express/exp_384_express_report_final_distrib_en.pdf [Accessed January 21, 2013].

Featherston, C.R. et al., 2015. Mediating and catalysing innovation: A framework for anticipating the standardisation needs of emerging technologies. Technovation, (in press). Available at: http://www.sciencedirect.com/science/article/pii/S0166497215000772.

Foray, D., 1998. Standards and innovation in technological dynamics. StandardView, 6(2), pp.81-84.

Garcia, D.L., 1993. A New Role for Government in Standards Setting? StandardView, 1(2), pp.2-10.

Garcia, D.L., 2004. Standards for Standard Setting: Contesting the Organizational Field. In S. Bolin, ed. The Standards Edge: Dynamic Tension. Ann Arbor: Sheridan Books, pp. 15-30.

Garcia, D.L., Leickly, B.L. \& Willey, S., 2005. Public and Private Interests in Standard Setting: Conflict or Convergence. In S. Bolin, ed. The Standards Edge: Future Generation. Ann Arbor: Sheridan Books, pp. 117-140.

Garcia, M. \& Bray, O., 1997. Fundamentals of technology roadmapping, Albuquerque.

Groenveld, P., 2007. Roadmapping integrates business and technology. Research-Technology Management, 50(6), pp.49-58.

Hanseth, O., Monteiro, E. \& Hatling, M., 1996. Developing information infrastructure: The tension between standardization and flexibility. Science, Technology \& Human Values, 21(4), pp.407-426.

Hawkins, R.W., 1995. Introduction: addressing the problematique of standards and standardization. In R. Hawkins, R. Mansell, \& J. Skea, eds. Standards, Innovation and Competitiveness. Cheltenham, The United Kingdom: Edward Elgar Publishing Ltd, pp. 1-6.

Ho, J.-Y., 2014. Standardization Roadmapping : Cases of ICT Systems Standards. STI Policy Review, 5(1), pp.1-33.

Ho, J.-Y., Featherston, C. \& O’Sullivan, E., 2014. A Systematic Process for Structuring Successive Roadmapping Exercises for Emerging Technologies: Lessons from Additive Manufacturing in the US. In 5th International Conference on Future-Oriented Technology Analysis (FTA). Brussels.

Hogan, M. et al., 2011. NIST Cloud Computing Standards Roadmap - Version 1.0, Available at: http://www.nist.gov/itl/cloud/upload/NIST_SP-500-291_Jul5A.pdf [Accessed November 10, 2013].

Hogan, O., Sheehy, C. \& Jayasuriya, R., 2015. The Economic Contribution of Standards to the UK Economy, London. 
Ibrahim, E., 2009. May 19-20 Smart Grid Standards Interoperability Interm Roadmap Workshop Overview, Available at: http://collaborate.nist.gov/twikisggrid/pub/_SmartGridInterimRoadmap/InterimRoadmapWorkshop2/SG_may1920_workshop_050809b_NISTapproved.ppt [Accessed March 20, 2014].

Jakobs, K., Lemstra, W. \& Hayes, V., 2011. Creating a wireless LAN standard: IEEE 802.11. In W. Lemstra, V. Hayes, \& J. Groenewegen, eds. The Innovation Journey of Wi-Fi. Cambridge: Cambridge University Press, pp. 53-109.

Kindleberger, C.P., 1983. Standards as Public, Collective and Private Goods. Kyklos, 36(3), p.377.

Kostoff, R.N. \& Schaller, R.R., 2001. Science and technology roadmaps. IEEE Transactions on Engineering Management, 48(2), pp.132-143.

Langlois, R.N., 2001. Technological Standards, Innovation, and Essential Facilities: Towards a Schumpeterian Post-Chicago Approach. In J. Ellig, ed. Dynamic Competition and Public Policy: Technology, Innovation, and Antitrust Issues. Cambridge, UK: Cambridge University Press, pp. 193-228.

Lundvall, B.-Å, 1992. National Systems of Innovation: Towards a Theory of Innovation and Interactive Learning, London: Pinter Pub Ltd.

Lyytinen, K., Keil, T. \& Fomin, V., 2008. A Framework to Build Process Theories of Anticipatory Information and Communication Technology (ICT) Standardizing. International Journal of IT Standards and Standardization Research, 6(1), pp.1-38.

Mansell, R., 1995. Standards, industrial policy and innovation. In R. Hawkins, R. Mansell, \& R. Skea, eds. Standards, Innovation and Competitiveness. Cheltenham, The United Kingdom: Edward Elgar Publishing Ltd, pp. 213-227.

Miao, X. et al., 2012. Comparing Smart Grid Technology Standards Roadmap of The IEC, NIST and SGCC. In 2012 China International Conference on Electricity Distribution. Shanghai: IEEE, pp. 1-4.

Min, J.-H., Cho, P.-D. \& Hahm, J.-H., 2012. Framework for making standardization roadmap and strategy. In Korea Information and Communications Engineering Conference. Busan, pp. 730-740.

Moreton, R., 1999. Standards, Strategy and Evaluation. In K. Jakobs, ed. Information Technology Standards and Standardization: A Global Perspective. London: Idea Group Publishing, pp. 103-115.

Narayanan, V.K. \& Chen, T., 2012. Research on technology standards: Accomplishment and challenges. Research Policy, 41(8), pp.1375-1406.

NIST, 2010a. NIST Framework and Roadmap for Smart Grid Interoperability Standards, Release 1.0, Washington DC. Available at: http://www.nist.gov/public_affairs/releases/upload/smartgrid_interoperability_final.pdf [Accessed February 17, 2015].

NIST, 2012. NIST Framework and Roadmap for Smart Grid Interoperability Standards, Release 2.0, Available at: http://www.nist.gov/smartgrid/upload/NIST_Framework_Release_2-0_corr.pdf [Accessed October 29, 2013].

NIST, 2014. NIST Framework and Roadmap for Smart Grid Interoperability Standards, Release 3.0, Gaithersburg, MD. Available at: http://www.nist.gov/smartgrid/upload/NIST-SP-1108r3.pdf [Accessed October 26, 2015].

NIST, 2010b. NIST Summary of the Responses to the National Science and Technology Council's SubCommittee on Standards Request-for-Information : Effectiveness of Federal Agency Participation in 
Standardization in Select Technology Sectors, Available at:

http://www.nist.gov/standardsgov/upload/RFI-Summary-5-13-final2.pdf [Accessed November 22, 2012].

NPE, 2010. The German Standardization Roadmap for Electromobility - Version 1.0.1, Berlin. Available at: http://www.vde.com/en/dke/std/Documents/The German Standardization Roadmap for Electromobility2.pdf [Accessed March 24, 2014].

NPE, 2012. The German Standardization Roadmap for Electromobility - Version 2, Available at: http://www.vde.com/en/dke/std/Documents/E-Mobility_Normungsroadmap_V2_EN.pdf [Accessed November 10, 2013].

NSTC, 2011. Federal Engagement in Standards Activities to Address National Priorities: Background and Proposed Policy Recommendations, Available at: http://www.whitehouse.gov/sites/default/files/microsites/ostp/federal_engagement_in_standards_activities _october12-final.pdf [Accessed November 22, 2012].

OCST, 1993. Voluntary Industry Standards and Their Relationship to Government Programs, Washington, D.C. Available at: http://www.strategicstandards.com/files/GovernmentStandards.pdf [Accessed September 10, 2015].

OTA, 1992. Global Standards: Building Blocks for the Future, Washington, DC. Available at: http://documents.irevues.inist.fr/handle/2042/28480 [Accessed December 5, 2013].

Phaal, R., Farrukh, C.J.P. \& Probert, D.R., 2010. Roadmapping for strategy and innovation: Aligning Technology and Markets in a Dynamic World, Cambridge: University of Cambridge, Institute for Manufacturing.

Phaal, R. \& Muller, G., 2009. An architectural framework for roadmapping: Towards visual strategy. Technological Forecasting and Social Change, 76(1), pp.39-49.

Popper, R., 2008. Foresight Methodology. In L. Georghiou et al., eds. The Handbook of Technology Foresight. Cheltenham: Edward Elgar Publishing, pp. 44-88.

Porter, M.E., 1990. The Competitive Advantage of Nations. Harvard Business Review, 68(2), pp.73-93.

Repussard, J., 1995. Problems and issues for public sector involvement in voluntary standardization. In R. Hawkins, R. Mansell, \& J. Skea, eds. Standards, Innovation and Competitiveness. Cheltenham, The United Kingdom: Edward Elgar Publishing Ltd, pp. 62-66.

Scapolo, F. et al., 2014. How will standards facilitate new production systems in the context of EU innovation and competitiveness in 2025?, Brussel.

Shurmer, M. \& Lea, G., 1995. Standardization and Intellectual Property Rights : A Fundamental Dilemma?, $3(2)$.

Smith, K., 1997. Economic Infrastructures and Innovation Systems. In C. Edquist, ed. Systems of Innovation: Technologies, Institutions and Organizations. London: Pinter, pp. 86-106.

Swann, G.M.P., 2000. The economics of standardization, Available at: http://scholar.google.com/scholar?hl=en\&btnG=Search\&q=intitle:THE+ECONOMICS+OF+STANDAR DIZATION\#1 [Accessed August 11, 2013].

Swann, G.M.P., 2010. The Economics of Standardization: An Update, Available at: http://www.bis.gov.uk/feeds/ /media/ED32CDA672764D7C8AC2F4E323581010.ashx [Accessed April 17, 2012]. 
Swann, G.M.P. \& Lambert, R., 2010. Why do Standards Enable and Constrain Innovation? In J. C. Gratz \& K. Jakobs, eds. Services Standardisation. Proceedings of the 15th EURAS Conference. EURAS contributions to standardisation research. Mainz Academic Publishers.

Tassey, G., 2000. Standardization in technology-based markets. Research Policy, 29(4-5), pp.587-602.

Tassey, G., 2014. The Economic Nature of Knowledge Embodied in Standards for Technology-Based Industries. In C. Antonelli \& A. N. Link, eds. Routledge Handbook of the Economics of Knowledge. New York: Routledge.

TTA, 2013. ICT Standardization Strategy Map Ver.2013, Sungnam.

Van de Ven, A.H., 1993. A community perspective on the emergence of innovations. Journal of Engineering and Technology Management, 10(1-2), pp.23-51.

De Vries, H.J., 1999. Standardiztion: A Business Approach to the Role of National Standardization Organizations, Dordrecht, The Netherlands: Kluwer Academic Publishers.

Yoo, Y., Lyytinen, K. \& Yang, H., 2005. The role of standards in innovation and diffusion of broadband mobile services: The case of South Korea. The Journal of Strategic Information Systems, 14(3), pp.323-353. 